\title{
Heart and lung transplantation in pulmonary arterial hypertension related to congenital heart disease: an unusual indication
}

\author{
Rosaria Barracano ${ }^{1,2}$, Heba Nashat ${ }^{1,3}$, Andrew Constantine $e^{1,3}$ and Konstantinos Dimopoulos ${ }^{1,3^{*}}$ (D)
}

\begin{abstract}
Background: Eisenmenger syndrome is a multisystem disorder, characterised by a significant cardiac defect, severe pulmonary hypertension and long-standing cyanosis. Despite the availability of pulmonary hypertension therapies and improved supportive care in specialist centres, Eisenmenger patients are still faced with significant morbidity and mortality.

Case presentation: We describe the case of a 44-year-old woman with Eisenmenger syndrome secondary to a large secundum atrial septal defect. Her pulmonary vascular disease was treated with pulmonary vasodilators, but she experienced a progressive decline in exercise tolerance, increasing atrial arrhythmias, resulting in referral for transplantation. Her condition was complicated by significant recurrent haemoptysis in the context of extremely dilated pulmonary arteries and in-situ thrombosis, which prompted successful heart and lung transplantation. She made a slow recovery but remains well 3 years post-transplant.

Conclusions: Patients with Eisenmenger syndrome secondary to a pre-tricuspid lesion, such as an atrial septal defect have a natural history that differs to patients with post-tricuspid shunts; the disease tends to present later in life but is more aggressive, prompting early and aggressive medical intervention with pulmonary arterial hypertension therapies. This case illustrates that severe recurrent haemoptysis can be an indication for expediting transplantation in Eisenmenger syndrome patients.
\end{abstract}

Keywords: Eisenmenger syndrome, Congenital heart disease, Heart and lung transplantation

\section{Background}

Pulmonary arterial hypertension (PAH) is a common complication among patients with congenital heart disease (CHD) $[1,2]$. In the presence of an unrepaired left-to-right shunt, pressure and/or volume overload of the pulmonary circulation leads to vascular remodelling and dysfunction, resulting in a progressive rise in pulmonary vascular resist-

\footnotetext{
* Correspondence: k.dimopoulos02@gmail.com

${ }^{1}$ Adult Congenital Heart Centre and National Centre for Pulmonary

Hypertension, Royal Brompton Hospital, Sydney Street, London SW3 6NP, UK

${ }^{3}$ National Heart and Lung Institute, Imperial College, London, UK

Full list of author information is available at the end of the article
}

ance and right ventricular overload [3]. There is growing evidence to support the use of PAH therapies in PAH associated with CHD (PAH-CHD) population, but despite recent advances, mortality remains high. Patients with severe $\mathrm{PAH}$ with an inadequate response to PAH therapy should be considered for transplantation [4]. We present the case of a patient with severe $\mathrm{PAH}$ and a large secundum atrial septal defect (ASD), who was referred to transplantation due to inadequate response to PAH therapy. Transplantation was expedited after she presented with recurrent haemoptysis in the presence of progressive, massive pulmonary artery (PA) dilatation.

C C The Author(s). 2020 Open Access This article is licensed under a Creative Commons Attribution 4.0 International License, which permits use, sharing, adaptation, distribution and reproduction in any medium or format, as long as you give appropriate credit to the original author(s) and the source, provide a link to the Creative Commons licence, and indicate if changes were made. The images or other third party material in this article are included in the article's Creative Commons licence, unless indicated otherwise in a credit line to the material. If material is not included in the article's Creative Commons licence and your intended use is not permitted by statutory regulation or exceeds the permitted use, you will need to obtain permission directly from the copyright holder. To view a copy of this licence, visit http://creativecommons.org/licenses/by/4.0/ The Creative Commons Public Domain Dedication waiver (http://creativecommons.org/publicdomain/zero/1.0/) applies to the data made available in this article, unless otherwise stated in a credit line to the data. 


\section{Case presentation}

A 44-year-old woman was referred to our service in 2002, with an established diagnosis of a large secundum ASD. At baseline, she had resting oxygen saturations of $97 \%$ on air. At right heart catheterisation (RHC), there was no step-up in saturations at the atrial or ventricular level. A mean pulmonary artery pressure (mPAP) of $53 \mathrm{mmHg}$ was measured, with a pulmonary vascular resistance (PVR) of 12.7 WU, and PVR index (PVRI) of 22 WU.m ${ }^{2}$. Following multi-disciplinary team discussion, ASD closure was contra-indicated due to the presence of severe pulmonary vascular disease. She was commenced on bosentan, an endothelin receptor antagonist. Computed tomography (CT) at the time of presentation also revealed dilated central pulmonary arteries (main PA diameter $41 \mathrm{~mm}$, right PA diameter $38 \mathrm{~mm}$ ), with no evidence of thrombosis.

The patient remained stable and active for several years, even periodically attending gym classes, until 2010 when she reported decreasing exercise tolerance and was noted to be newly cyanosed at rest. Resting oxygen saturations were $84 \%$ on air. She was commenced on combination PAH therapy with the addition of sildenafil and remained relatively stable until 2012, when she was urgently admitted to hospital due to haemoptysis. CT pulmonary angiography (CTPA) revealed massive progressive dilatation of the proximal pulmonary arteries with an aneurysmal right pulmonary artery measuring $57 \mathrm{~mm}$ with in-situ thrombosis (Fig. 1). There were no obvious targets for bronchial artery embolisation. The thrombi appeared chronic in nature. There were also changes consistent with haemorrhage in the right upper lobe. The haemoptysis was selflimiting, and she did not require blood transfusions, ventilatory or inotropic support.

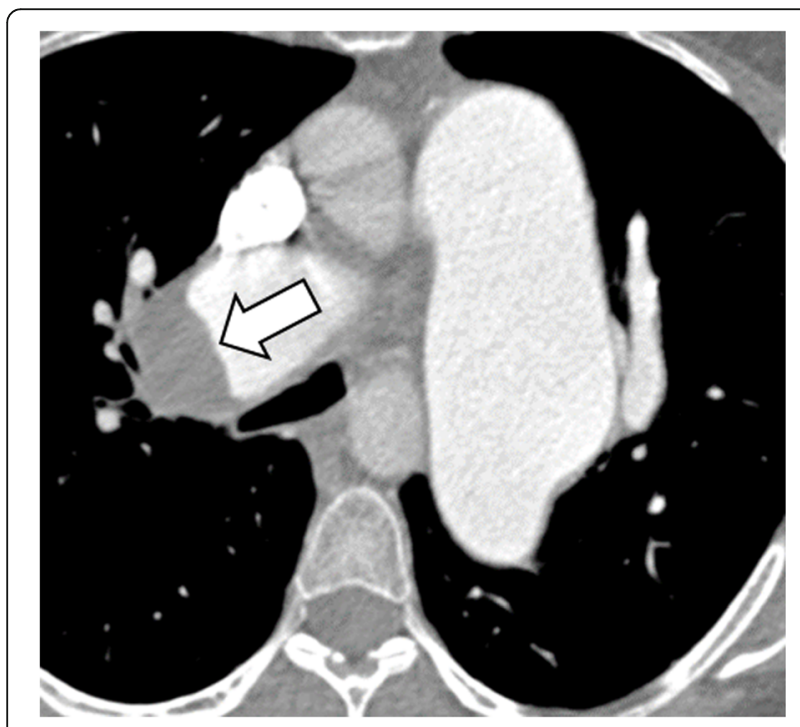

Fig. 1 Computed tomography of pulmonary arteries, illustrating pulmonary artery dilatation and in-situ thrombus (arrow)
In the subsequent months she experienced progressive deterioration in exercise capacity and dizziness on effort, with echocardiographic evidence of deteriorating right ventricular function (Fig. 2). A 6-min walk test was performed, during which she achieved a distance of $220 \mathrm{~m}$. Saturations dropped to $71 \%$ on exercise and the Borg score at peak exertion was 9 out of 10 (almost maximal perceived exertion). Sildenafil was uptitrated, but she declined introduction of prostanoid therapy at this stage. The patient was referred for transplantation assessment. The outcome of this assessment was that she was a potential candidate for heart and lung transplantation (HLT) but was deemed to be "too well" for active listing. Over the following 9 months, she experienced multiple episodes of decompensated heart failure triggered by arrhythmias and underwent successful atrial flutter ablation. Six months later she presented with atrial fibrillation with a fast ventricular response. She underwent successful pharmacological cardioversion with amiodarone. This medication was continued long-term to maintain sinus rhythm.

Over the next several months she presented with recurrent haemoptysis with three further episodes. Repeat RHC revealed a mPAP of $52 \mathrm{mmHg}$, a PVR of $11.3 \mathrm{WU}$ (PVRI 20.3 WU. ${ }^{2}$ ) without a significant left-to-right shunt. There was a drop in the 6-min walk test distance from $300 \mathrm{~m}$ to $220 \mathrm{~m}$, and the b-type natriuretic peptide level rose from 149 to $568 \mathrm{ng} / \mathrm{L}$ (normal< $20 \mathrm{ng} / \mathrm{L}$ ). During these episodes, she was observed in hospital and was treated with cough suppressants, antibiotics when there were features of precipitation respiratory tract infection, and blood products to keep her haematocrit at a level appropriate for her resting oxygen saturation. She was switched from bosentan to macitentan $10 \mathrm{mg}$ and she was discharged from hospital, but her condition was further complicated by amiodarone-induced thyrotoxicosis. Amiodarone was substituted with a low-dose beta blocker.

A further CTPA showed progressive massive dilatation of the pulmonary arteries, resulting in marked right middle lobe atelectasis secondary to compression and deviation of the middle lobe bronchus by the inferior aspect of the massively dilated right PA (right PA diameter $70 \mathrm{~mm}$; Fig. 3). Similar to the CT after the first episode of haemoptysis, there were no clear targets for intervention and embolization. The risk of thrombectomy and aneurysm repair on cardiopulmonary bypass was felt to be preclusive and not necessarily helpful in preventing further haemoptysis. Lobectomy was not considered as a viable option in the absence of a target vessel and a single affected lung lobe. In view of the recurrent episodes of haemoptysis, the extreme aneurysmal dilatation of the pulmonary arteries and the inadequate response to PAH therapies despite escalation, she was referred back to the transplant centre for immediate listing. Nebulised iloprost was also commenced, 


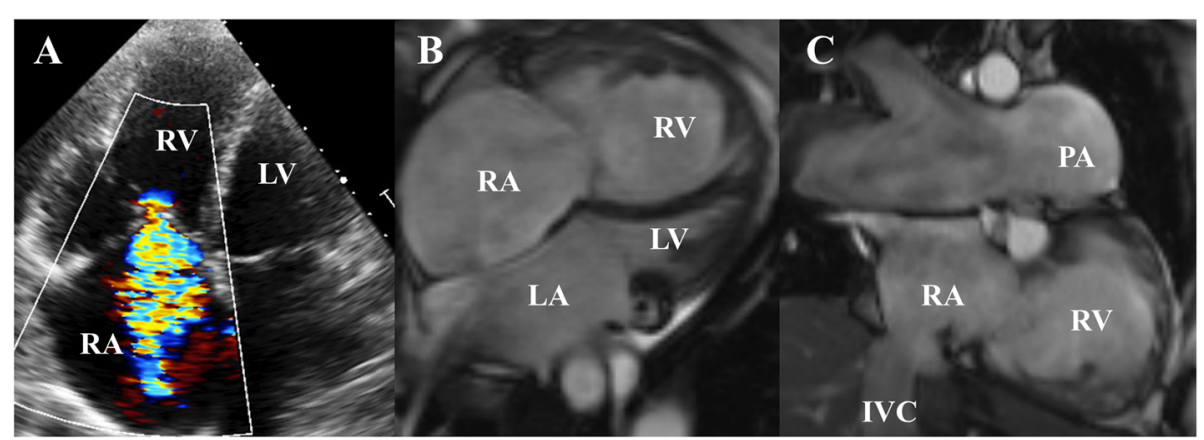

Fig. 2 a Transthoracic echocardiographic apical 4-chamber view illustrating a severely dilated right ventricle (RV) and right atrium (RA), a small under-filled left ventricle (LV) and severe tricuspid regurgitation. b, c: Cardiovascular magnetic resonance images of the same patient, demonstrating severe RV and RA dilatation, a dilated inferior vena cava (IVC) suggestive of raised central venous pressure, and a severely dilated pulmonary artery (PA) with sluggish flow and in-situ thrombosis

albeit with an inadequate response. A few months later, she underwent HLT. The operation was complicated by prolonged stay in the intensive care unit necessitating a slow respiratory wean, acute kidney injury requiring haemodialysis, sternal dehiscence and a candida infection. After a 5-month hospital stay, she was discharged home. At 3 years follow-up from the time of the transplant, she remained well with a good exercise capacity, swimming three times a week and regularly attending a gym.

\section{Discussion and conclusions}

The European Society of Cardiology/European Respiratory Society (ESC/ERS) guidelines provide recommendations for the management of all types of $\mathrm{PAH}$, including $\mathrm{PAH}-\mathrm{CHD}$ [5]. However, there is still limited evidence on the management of PAH-CHD patients, both in relation to the use of $\mathrm{PAH}$ therapies, and also with regards to risk assessment and timing of transplantation. Patients with $\mathrm{PAH}-\mathrm{CHD}$ are

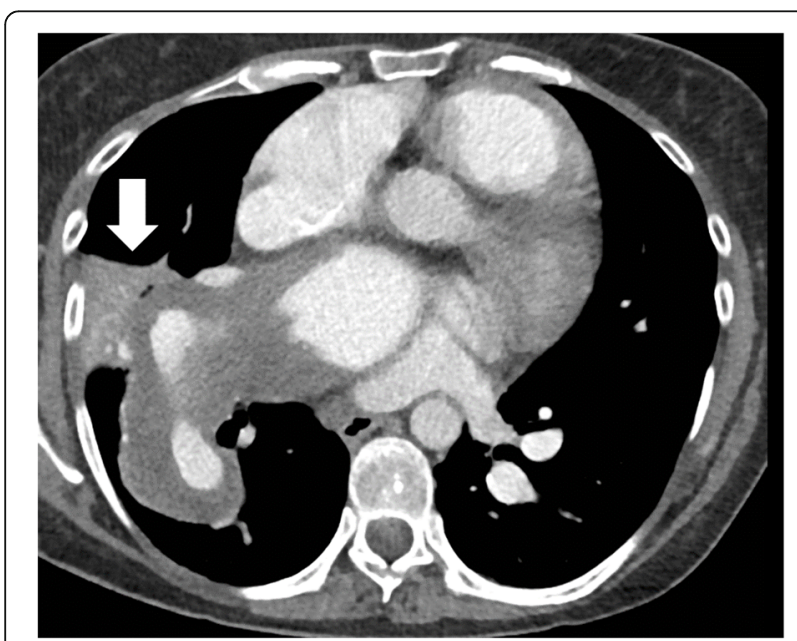

Fig. 3 Computed tomography image illustrating dilatation of the right pulmonary artery, with in-situ thrombus and right middle lobe atelectasis (arrow) a heterogeneous population that spans from ES to patients with left-to-right shunts, small defects or previously repaired defects. The clinical phenotype depends on the size and position of the defect and the degree of pulmonary vascular disease. In the absence of PAH, defect repair is recommended and can prevent future development of arrhythmias or PAH. The presence of significant pre-operative $\mathrm{PAH}$, however, is associated with adverse events following defect closure, including heart failure and death and so repair is avoided [6]. For patients with a mild-moderate degree of pulmonary hypertension in the presence of a leftto-right shunt, management decisions can be complex and require multi-disciplinary discussion in a specialist centre. Initiation of pulmonary vasodilator therapy should be carefully considered as it may increase left-to-right shunting. Furthermore, incomplete (fenestrated) defect repair may have a role in selected cases.

Little is known why patients with pre-tricuspid shunts, such as in the case described, develop severe pulmonary vascular disease. Indeed, while large ventricular septal defects (VSDs), large patent ducts or aortopulmonary windows result in significant pressure overload and shear stress to pulmonary arterioles, isolated ASDs would not normally be expected to trigger pulmonary vascular disease. Despite this, a proportion of patients with large ASDs may develop near systemic vascular resistance of the pulmonary vasculature, with reversal of the shunt and a clinical picture in keeping with ES. It has been hypothesised that such patients may have an underlying genetic disposition to developing pulmonary vascular disease [3].

In adult patients with ES associated with an ASD, the cardiac phenotype differs from those with a VSD. In the latter, the right ventricle (RV) is typically hypertrophied, but is not significantly dilated, and systolic function is often preserved for several years or decades after initial presentation. In the former, the RV is typically severely dilated and significantly impaired, with eccentric hypertrophy and severe right and left atrial dilatation, often 
associated with significant tricuspid regurgitation. Moreover, clinical presentation is often late, after the second decade of life, unlike patients with large post-tricuspid shunts in whom PVD typically develops early in life (even though the Eisenmenger phenotype may not develop until the second decade of life). The presence of an atrial communication in patients e.g. with idiopathic PAH is believed to benefit the patient by providing some relief to the overloaded RV and boosting systemic cardiac output at the expense of cyanosis. However, it is not as efficient a "relief valve" as a VSD or patent ductus arteriosus.

Patients with "Eisenmenger ASD" were included in the BREATHE- 5 study, the first randomised trial of PAH therapy in ES. Subsequent subgroup analysis confirmed the efficacy of bosentan in improving 6-min walk distance in this cohort [7]. Current guidelines recommend lung transplantation (LT) or HLT for patients with severe PAH who fail pharmacological treatment [8] and remain in functional class III or IV [9]. The only definitive treatment for ES is LT with shunt closure or HLT [10, 11]. Nevertheless, the general lack of organs and suboptimal survival after LT or HLT underline the need for alternative therapeutic options [12].

While progressive, refractory heart failure is the most common indication for transplantation assessment of $\mathrm{PAH}$ patients, other signs of disease progression, such as haemoptysis and progressive PA dilatation, need to be considered. Although mild haemoptysis is common in this cohort, recurrent, progressive and large-volume haemoptysis is rarer and should be an immediate trigger for clinical re-assessment and expedited referral for transplant assessment.

\begin{abstract}
Abbreviations
ASD: Atrial septal defect; BNP: B-type natriuretic peptide; CHD: Congenital heart disease; CT: Computed tomography; CTPA: Computed tomography pulmonary angiography; ES: Eisenmenger syndrome; HLT: Heart and lung transplantation; LT: Lung transplantation; mPAP: mean pulmonary arterial pressure; PA: Pulmonary artery; PAH: Pulmonary arterial hypertension; PAHCHD: Pulmonary arterial hypertension related to congenital heart disease; PVR(I): pulmonary vascular resistance (index); RHC: Right heart catheterisation; RV: Right ventricle; VSD: Ventricular septal defect
\end{abstract}

\section{Acknowledgements}

Not applicable.

\begin{abstract}
About this supplement
This article has been published as part of Journal of Congenital Cardiology Volume 4 Supplement 1 2020: Unmet needs in Pulmonary Hypertension associated with Adult Congenital Heart Disease (ACHD-PH). The full contents of the supplement are available at https://jcongenitalcardiology. biomedcentral.com/articles/supplements/volume-4-supplement-1
\end{abstract}

\section{Authors' contributions}

$\mathrm{RB}, \mathrm{HN}, \mathrm{AC}$ and $\mathrm{KD}$ contributed to the conception and planning of the case report. RB drafted the case report. $H N, A C$, and $K D$ revised the report significantly. $\mathrm{RB}, \mathrm{HN}, \mathrm{AC}$ and $\mathrm{KD}$ approved the final manuscript for publication.

\section{Funding}

Medical writing support was provided by nspm Itd, Meggen, Switzerland. The manuscript was funded by a Medical and Educational Goods and
Services (MEGS) grant and Actelion Pharmaceuticals UK Limited (who had no influence on manuscript writing).

Availability of data and materials

Not applicable.

\section{Ethics approval and consent to participate}

Informed consent was gained for the patient to form the subject of this case report in line with CARE guidance. No special ethics approval was necessary for this case report.

\section{Consent for publication}

The patient gave consent for their clinical details along with any identifying images to be published in this study.

\section{Competing interests}

Dr. Nashat has received a personal travel grant from Actelion Pharmaceuticals UK. Dr. Constantine has received a personal educational grant from Actelion Pharmaceuticals UK. Dr. Dimopoulos has received nonfinancial support from Actelion Pharmaceuticals; and has been a consultant to and received grants and personal fees from Actelion Pharmaceuticals, Pfizer, GlaxoSmithKline, and Bayer/MSD. Dr. Barracano has no competing interests to disclose.

\section{Author details}

${ }^{1}$ Adult Congenital Heart Centre and National Centre for Pulmonary Hypertension, Royal Brompton Hospital, Sydney Street, London SW3 6NP, UK. ${ }^{2}$ Division of Cardiology, Department of Cardio-Thoracic and Respiratory Sciences, University of Campania "Luigi Vanvitelli" and A.O. dei Colli Monaldi Hospital, Naples, Italy. ${ }^{3}$ National Heart and Lung Institute, Imperial College, London, UK

Received: 12 November 2020 Accepted: 12 November 2020

Published: 16 December 2020

\section{References}

1. D'Alto M, Mahadevan VS. Pulmonary arterial hypertension associated with congenital heart disease. Eur Respir Rev. 2012;21(126):328-37. Available from. https://doi.org/10.1183/09059180.00004712.

2. Kempny A, Hjortshøj CS, Gu H, Li W, Opotowsky AR, Landzberg MJ et al. Predictors of death in contemporary adult patients with Eisenmenger syndrome: a multicenter study. Circulation. 2017;135(15):1432-1440. Available from: doi:https://doi.org/10.1161/circulationaha.116.023033.

3. Dimopoulos K, Wort SJ, Gatzoulis MA. Pulmonary hypertension related to congenital heart disease: a call for action. Eur Heart J. 2014;35(11):691-700. Available from. https://doi.org/10.1093/eurheartj/eht437.

4. López-Meseguer M, Quezada CA, Ramon MA, Lázaro M, Dos L, Lara A, et al. (REHAP investigators). Lung and heart-lung transplantation in pulmonary arterial hypertension. PLoS One. 2017;12(11):e0187811. Available from. https://doi.org/10.1371/journal.pone.0187811.

5. Authors/Task Force Members, Galiè N, Humbert M, Vachiery J-L, Gibbs S, Lang I, Torbicki A, et al. 2015 ESC/ERS Guidelines for the diagnosis and treatment of pulmonary hypertension: The Joint Task Force for the Diagnosis and Treatment of Pulmonary Hypertension of the European Society of Cardiology (ESC) and the European Respiratory Society (ERS) Endorsed by: Association for European Paediatric and Congenital Cardiology (AEPC), International Society for Heart and Lung Transplantation (ISHLT). Eur Heart J. 2016;37(1):67-119. Available from. https://doi.org/10.1093/eurheartj/ehv317.

6. Konstantinides S, Geibel A, Olschewski M, Görnandt L, Roskamm H, Spillner G, Just H, Kasper W. A comparison of surgical and medical therapy for atrial Septal defect in adults. N Engl J Med. 1995;333(8):469-73. Available from. https://doi.org/10.1056/NEJM199508243330801.

7. Galiè N, Beghetti M, Gatzoulis MA, Granton J, Berger RMF, Lauer A, et al. Bosentan therapy in patients with Eisenmenger syndrome: a multicenter, double-blind, randomized, placebo-controlled study. Circulation. 2006;114(1): 48-54. Available from. https://doi.org/10.1161/circulationaha.106.630715.

8. Galie N, Corris PA, Frost A, Girgis RE, Granton J, Jing ZC, et al. Updated treatment algorithm of pulmonary arterial hypertension. J Am Coll Cardiol. 2013;62(25S):D60-72. Available from. https:/doi.org/10.1016/j.jacc.2013.10.031. 
9. McLaughlin W, Shillington A, Rich S. Survival in primary pulmonary hypertension: the impact of epoprostenol therapy. Circulation. 2002;106(12): 1477-82. Available from. https://doi.org/10.1161/01.cir.0000029100.82385.58.

10. Waddell TK, Bennet $L$, Kennedy R, et al. Heart-lung transplantation for Eisenmenger syndrome. J Heart Lung Transplant. 2002;21(7):731-7. Available from. https://doi.org/10.1016/S1053-2498(01)00420-X.

11. Stoica SC, McNeil KD, Perreas K, et al. Heart-lung transplantation for Eisenmenger syndrome: early and long-term results. Ann Thorac Surg. 2001; 72(6):1887-91. Available from. https://doi.org/10.1016/S0003-4975(01)03099-5.

12. Nashat $\mathrm{H}$, Kempny A, Dimopoulos K, et al. Eisenmenger syndrome: current perspectives. Res Rep Clin Cardiol. 2017;2017(8):1-12. Available from. https:// doi.org/10.2147//rcc.s117838.

\section{Publisher's Note}

Springer Nature remains neutral with regard to jurisdictional claims in published maps and institutional affiliations.

Ready to submit your research? Choose BMC and benefit from:

- fast, convenient online submission

- thorough peer review by experienced researchers in your field

- rapid publication on acceptance

- support for research data, including large and complex data types

- gold Open Access which fosters wider collaboration and increased citations

- maximum visibility for your research: over $100 \mathrm{M}$ website views per year

At $B M C$, research is always in progress.

Learn more biomedcentral.com/submissions 